\title{
Light and electron microscopic immunocytochemical analysis of the dopamine innervation of the rat visual cortex
}

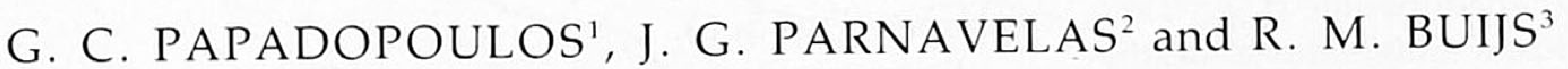 \\ 'Laboratory of Anatomy, Veterinary School, University of Thessaloniki, Thessaloniki 54006, Greece \\ ${ }^{2}$ Department of Anatomy and Developmental Biology, University College London, London WC1E 6BT, UK \\ ${ }^{3}$ Netherlands Institute for Brain Research, 1105AZ Amsterdam, The Netherlands
}

Received 10 October 1988; revised 9 December 1988; accepted 16 December 1988

\begin{abstract}
Summary
The dopaminergic innervation of the rat primary (area 17) and secondary (areas 18 and 18a) visual cortical areas was examined immunocy tochemically using an antiserum directed against dopamme. This innervation was characterized by the differential density of the respective afferents within individual visual areas. Area 18, especially its rostral part, was observed to receive a considerable amount of dopaminergic axons, whereas areas 17 and 18a were sparsely innervated. The innervation of all layers of area 18 seemed to consist to a considerable extent of axonal branches of radial fibres ascending from layer VI to layer I. At the ultrastructural level, dopamine profiles were found to display similar characteristics in all visual areas. Dopamine labelled axon-terminals and axonal varicosities, examined in single and serial ultrathin sections, were seen to form primarily asymmetrical synaptic contacts with dendritic profiles. These observations suggest a 'specific' innervation of cytoarchitectonically distinct cortical regions by dopaminergic axons.
\end{abstract}

\section{Introduction}

Evidence for a dopaminergic innervation of the cerebral cortex was first given when Thierry et al. (1973 a, b), using biochemical and lesion studies, suggested that dopamine (DA) in the rat neocortex does not solely represent a precursor of noradrenaline (NA). Subsequent anatomical studies confirmed that DAcontaining neurons localized in the mesencephalon innervate restricted cortical fields (Fuxe et al., 1974; Lindvall et al., 1974, 1978; Carter \& Fibiger, 1977; Emson \& Koob, 1978; Swanson, 1982; Lindvall \& Björklund, 1984). These fields include the medial prefrontal cortex, the lateral cortex around the rhinal sulcus, the anterior cingulate cortex and the entorhinal cortical area (Berger et al., 1974, 1976; Hökfelt et al., 1974 a, b; Lindvall et al., 1974, 1978; Fallon et al., 1978; Lewis et al., 1979; Van Eden et al., 1987).

Comparatively low levels of DA have been measured in other cortical regions of the rat (Emson \& Lindvall, 1979; Palkovits et al., 1979; Reader, 1981). It has been suggested that DA in these cortical areas is present as a precursor of NA as no labelled axons could be visualized in these regions after elimination of the noradrenergic afferents (Levitt \& Moore, 1978).
However, recent findings have suggested the existence of additional dopaminergic terminal fields in the cat and rat cerebral cortex. Törk \& Turner (1981), combining tracing techniques with catecholamine histofluorescence, provided evidence for DA projections from A10 to the visual cortex of the cat, while Berger et al. (1985) reported the presence of tyrosine hydroxylase immunoreactive fibres, following destruction of the cortical noradrenergic system, in discrete regions of the rat sensorimotor cortex, secondary visual cortical areas and retrosplenial cortex. The latter observations have been confirmed recently by Descarries et al. (1987) who utilized an autoradiographic procedure to visualize terminals in whole cerebral hemisphere slices incubated with tritiated DA. The present study examines the organization and ultrastructural features of the dopaminergic afferents of the visual cortical areas of the rat by using a specific antibody against the neurotransmitter itself. Immunohistochemistry with antibodies directed against DA, recently applied successfully in the rat CNS (Buijs et al., 1984; Onteniente et al., 1984; Voorn et al., 1986; Van Eden et al., 1987), permits direct visualization of 
DA-containing axons without previous chemical or surgical intervention.

\section{Materials and methods}

Twelve adult albino rats (eight Sprague-Dawley and four Wistar animals) of both sexes were used in this study. Animal and tissue preparation, and the immunocytochemical procedure applied to free-floating sections, were similar to those described previously (Papadopoulos et al., 1987, 1989). Briefly, animals were perfused under ether anaesthesia with a fixative solution containing $5 \%$ glutaraldehyde and $1 \%$ sodium metabisulphite in $0.05 \mathrm{M}$ cacodylate buffer at $\mathrm{pH}$ 7.5. Coronal sections through the occipital cortex were cut with a Vibroslice at $50 \mu \mathrm{m}$ and collected in $0.05 \mathrm{M}$ Tris buffer saline containing 1\% sodium metabisulphite, $\mathrm{pH} 7.5$. Sections were subsequently processed with the peroxidaseantiperoxidase immunocytochemical technique using an antiserum directed against DA. The preparation and characterization of the DA antiserum, which was used in a dilution of $1: 2500$, has been described elsewhere (Buijs et al., 1984; Geffard et al., 1984). Preabsorption of this antiserum with $10^{-5} \mathrm{M}$ synethetic DA or omission of the link antiserum from the peroxidase-antiperoxidase procedure eliminated all staining. However, the use of NA-absorbed antiserum revealed no difference in cortical staining compared with the non-absorbed DA antiserum.

\section{Results}

Dopamine afferents clearly showed a differential density within the various cytoarchitectonic fields of the visual cortex. Thus while the innervation of areas 17 and 18 a appeared very sparse, area 18 was found to receive a considerably greater density of DAimmunoreactive fibres especially $i_{i}$ the rostral portion (Fig. 1). The innervation of areas 17 and 18a consisted mainly of immunoreactive axonal branches distributed in layer VI with occasional short axonal segments scattered throughout the remaining of the cortical thickness (Figs 2, 4). Only in layer VI were we able to observe longer fibres running parallel to the subcortical white matter (Fig. 4).

The picture was considerably different within area 18 where long radial fibres traversing the whole thickness of the cortex could be followed in individual sections (Figs 3, 5). Interspersed between the radial fibres, and probably originating from them, were short immunoreactive segments. Radial axons appeared to originate from tangentially oriented fibres in layer VI which seemed to be the continuation of DA-labelled axons penetrating in large numbers from the entorhinal cortex into layer VI of the temporal cortex (Fig. 1). A few ascending radial fibres in area 18 were seen to penetrate into layer I while others made a hairpin bend at the level of layer II to descend to the lower layers. Morphologically, DA-labelled fibres exhibited similar features in all visual areas and in other cortical regions examined (entorhinal and temporal cortex). They were relatively thin and tortuous, bearing irregularly spaced varicosities of various shapes (Figs 5, 6).

Dopamine-immunoreactive profiles examined at the ultrastructural level, although rarely found in areas 17 and 18a, were differentiated as unmyelinated intervaricose axonal segments and varicosities filled with mitochondria and synaptic vesicles. The latter, when possible to discern due to the presence of the peroxidase reaction product, were usually pleomorphic in shape. Varicosities examined in single ultrathin sections through all visual areas were at times seen to form synaptic contacts with dendritic elements (Figs 9-11). However, analysis of series of 12-15 serial sections through 30 varicosities distributed throughout the visual cortex showed that nearly all $(27 / 30 ; 90 \%)$ formed conventional synapses with postsynaptic targets (Figs 7,8). Those that were not seen to form synaptic contacts were deep in layer VI where tissue preservation was not optimal. The majority of synapses showed asymmetrical specializations (Figs 7-9), but some symmetrical synaptic contacts were also observed (Figs 10,11). Postsynaptic targets were chiefly dendritic shafts of a wide range of diameters but also dendritic spines. Axosomatic synapses were not observed in this study although labelled terminals were sometimes seen adjacent to neuronal somata.

\section{Discussion}

\section{Methodological considerations}

The localization of DA in the cerebral cortex has been hampered by the presence of an extensive noradrenergic network. Some authors have attempted to differentiate between DA- and NA-containing fibres (Lindvall et al., 1974; Levitt et al., 1984), but morphological differences are not always clearly defined and have generally proven inadequate for the study of cortical DA systems. Until recently, the DA and NA axonal networks, which normally intermingle extensively in the cortex, could only be unravelled after

Fig. 1. Camera lucida drawing illustrating the distribution of dopamine-containing fibres in a coronal section through the occipital cortex of one hemisphere of the rat brain. The surface arrowheads indicate the borders of cortical areas 17, 18 and 18 a. Te, temporal cortex; Rs, retrosplenial cortex.

Figs 2, 3. Camera lucida drawings showing the distribution of dopamine-containing axons in coronal strips, between the pia and the subcortical white matter (WM), through areas 17 (Fig. 2) and 18 (Fig. 3) of the rat visual cortex. Scale bars: $100 \mu \mathrm{m}$. 

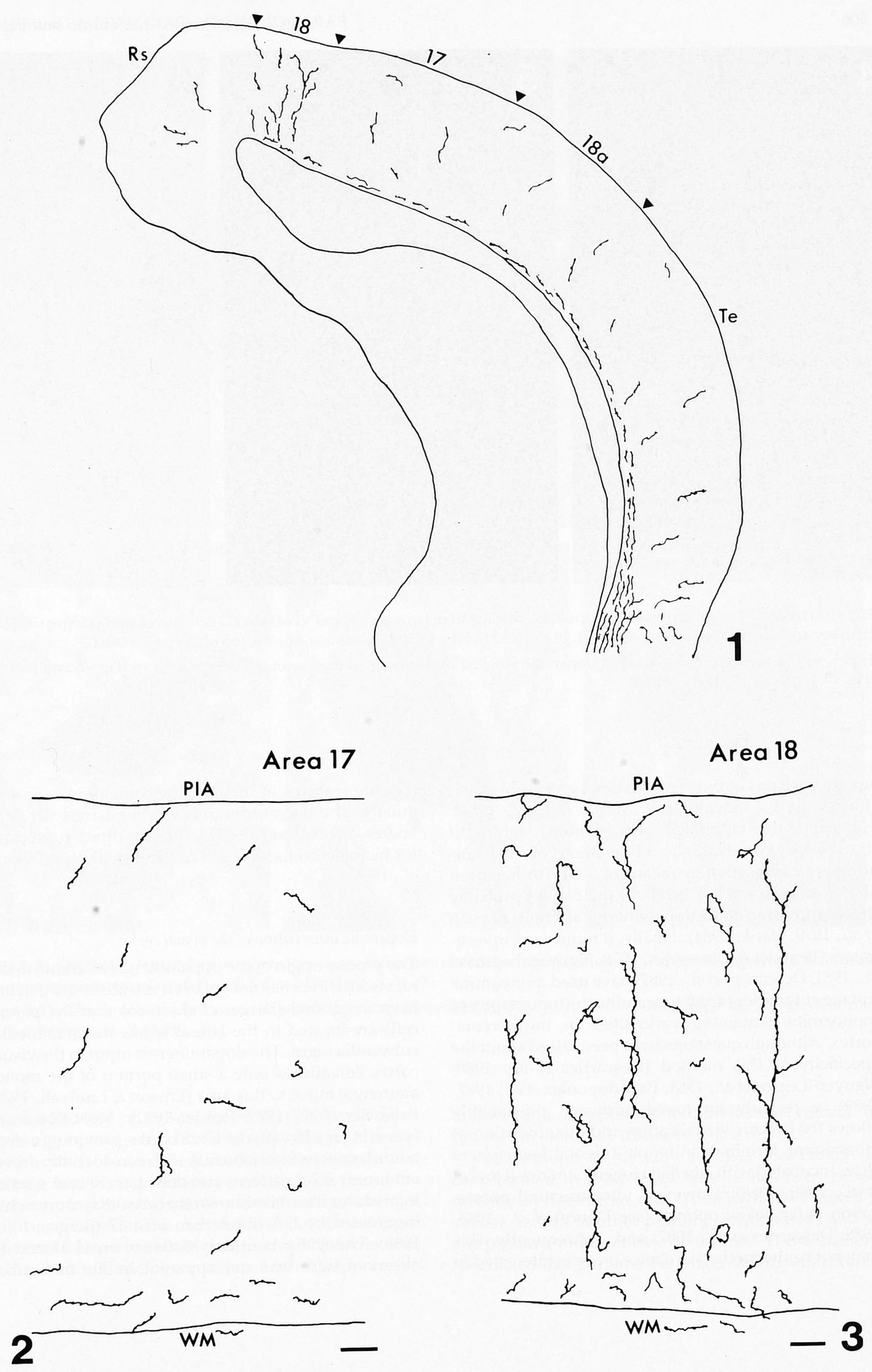

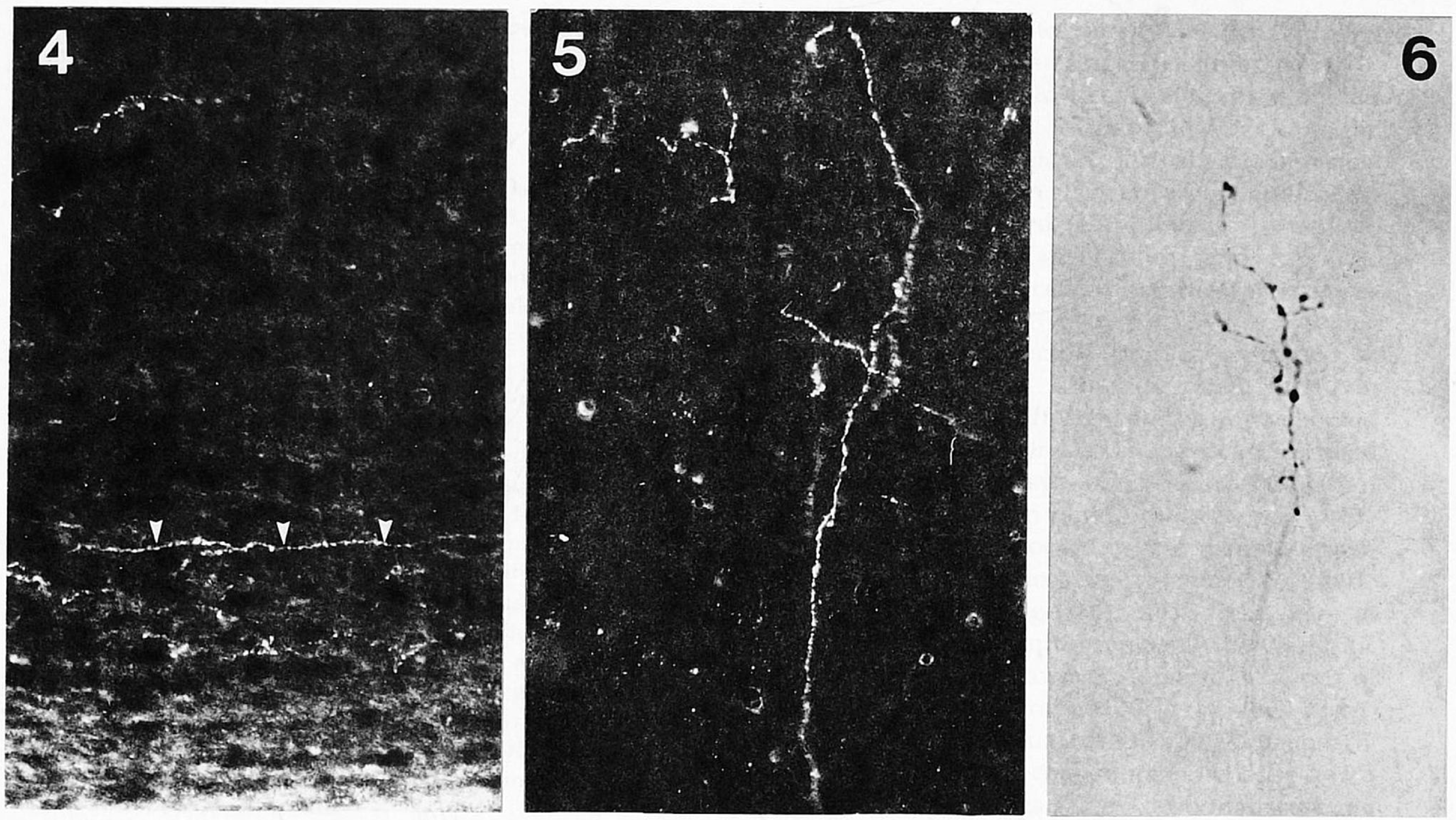

Fig. 4. Darkfield photomicrograph of dopamine-labelled fibres in layers V and VI of area 17. A relatively long tangential fibre (arrowheads) can be seen in deep layer VI. In this and in Figs 5 and 6, pia is towards the top of the page. $\times 300$.

Figs 5, 6. Photomicrographs of radial dopamine-labelled fibres in the supragranular layers of area 18 (Fig. 5) and area 17 (Fig. 6). Fig. 5, × 280; Fig. 6, $\times 900$.

selective lesions of the respective cell groups of origin (Björklund \& Lindvall, 1984; Moore \& Card, 1984). However, this approach also exhibits significant drawbacks. For example, elimination of the noradrenergic projection by means of 6-OHDA has been shown to increase DA levels in the cortex, probably due to sprouting of the dopaminergic afferents (Tassin et al., 1979; Harik, 1984). Finally, a number of investigators (Beaudet \& Descarries, 1978; Nguyen-Legros et al., 1981; Descarries et al., 1987) have used monoamine uptake autoradiography to examine the topography of monoamine-containing varicosities in the cerebral cortex. Although questions have been raised about the specificity of this method (Descarries et al., 1980; Nguyen-Legros et al., 1981; Papadopoulos et al., 1987, 1989), a recently improved approach presumably allows for specific vizualization and quantification of monoamine terminals in whole cerebral hemisphere slices incubated with labelled biogenic amines (Doucet et al., 1986, 1988). However, ultrastructural preservation is far below optimal (see Doucet et al., 1986, 1988; Descarries et al., 1987) and, consequently, this may not be the method of choice if one is interested in the fine features of monoamine-containing axon terminals. The use of immunocytochemistry with antibodies directed against DA offers a direct procedure for histological localization of the transmitter (Buijs et al., 1984).

\section{Dopamine innervation of the visual cortex}

The precise origin of the dopaminergic afferents to the rat visual cortex has not yet been established, but it has been suggested (Berger et al., 1985) that the parent cells are located in the lateral tegmental area/medial substantia nigra. The dopaminergic input to the visual cortex constitutes only a small portion of the monoaminergic input to this area (Emson \& Lindvall, 1979; Palkovits et al., 1979; Reader 1981). Most fibres are found in area 18 with the $17 / 18$ border providing a clear boundary between two areas with considerably different innervation patterns and densities. Recent studies in primates have also shown that area 18 is more richly innervated by DA fibres than area 17 (Berger et al., 1988). The sharp boundary between areas 17 and 18 observed here was not apparent in the autoradio- 

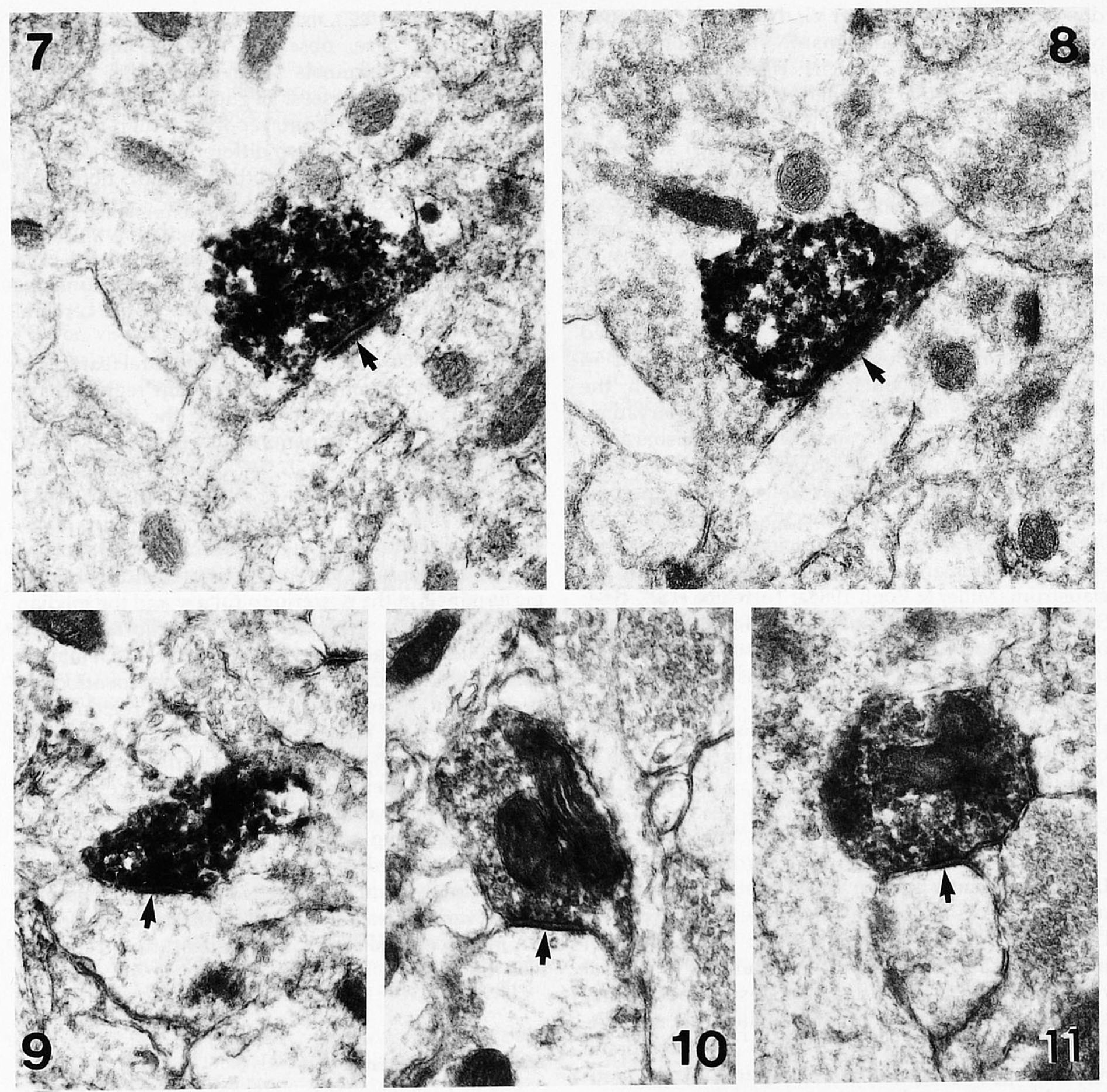

Figs 7, 8. Dopamine-labelled axon terminal in two sections from a series of serial sections in which it was observed to form an asymmetrical synapse (arrows) with a dendritic shaft. $\times 41250$.

Figs 9-11. Dopamine-labelled axon terminals forming asymmetrical (Fig. 9) or symmetrical (Figs 10, 11) axodendritic synapses (arrows). $\times 41250$.

graphic studies of Descarries et al. (1987) nor were there any uptake sites shown in area 17 except for the deep portion of layer VI. A similar shift in innervation density has been previously reported for the noradrenergic input in the monkey visual cortex, whereas in the same species the overall density of serotonergic afferents is lower in area 18 than in area 17 (Morrison \& Foote, 1986). These observations further support the notion of a more restricted brainstem control of cytoarchitectonically distinct cortical regions.

The question as to why the DA innervation is concentrated in layer VI of area 17 has been raised recently by Descarries et al. (1987) who also noted a similar pattern in other primary sensory areas and in the primary motor cortex of the rat. These authors speculated that perhaps the tangential organization of 
dopaminergic fibres in layer VI, the site of termination of axons arising predominantly from non-specific intralaminar thalamic nuclei (Herkenham, 1980), underlies a particular modulatory role for DA in these cortical areas.

Earlier studies by Montero et al. (1973) and more recent work by Espinoza \& Thomas (1983) have distinguished a number of retinotopically organized areas in the rat occipital cortex. The largest of these areas, the primary visual area, corresponds to area 17 as defined by cytoarchitectonic criteria. Six other representations of the visual field are located in the so-called extrastriate cortex, two of which, termed anteromedial and posteromedial, are confined in visual area 18. The anteromedial (AM) portion, the recipient of the heaviest dopaminergic innervation, has reciprocal ipsilateral connections with visual areas 17, 18a and with other sites in area 18 (Miller \& Vogt, 1984a; Torrealba et al., 1984) as well as both homotopic and heterotopic callosal connections (Miller \& Vogt, 1984b). It is also connected reciprocally with other sensory, motor and association areas and with the claustrum (Miller \& Vogt, 1984a; Torrealba et al., 1984; Sukekawa, 1988). This apparently associational nature of AM is supported by a behavioural study showing its importance for the learning of a visual-somesthetic conditional response (Torrealba et al., 1984). It may be that DA is involved in the integration of visual and other sensory and motor information in this portion of area 18.

\section{Ultrastructural localization of $D A$ in the visual cortex}

Little is presently known about the mode of termination of DA-containing axons in the cerebral cortex. Descarries and co-workers (1987), using electron microscope autoradiography in a number of cortical regions in the rat, reported that despite poor ultrastructural preservation in their material some DAlabelled terminals showed areas of membrane specializations suggestive of synaptic contacts. Considerably more information is given in recent immunocytochemical studies in the rat cortex. Thus
Van Eden et al. (1987), using the same DA antiserum as that utilized here, observed that the majority of dopaminergic terminals formed synaptic contacts with dendritic processes. Séguéla et al. (1988), also using the same antiserum, reported a high incidence of synaptic contacts in two different cortical areas. In an analysis of serial sections, these authors noted that $93 \%$ of DA varicosities formed synaptic contacts in the anteromedial cortex and $56 \%$ in the suprarhinal cortex. These observations suggest that there exist regional differences in the fine structural relationships of the DA inputs to different regions of the cerebral cortex.

Studies that examined the ultrastructural features of dopaminergic terminals in other brain regions have given varying accounts concerning the incidence of synapses made by dopaminergic neurons (Ajika \& Hökfelt, 1973; Wilson et al., 1977; Chetverukhin et al., 1979; Nguyen-Legros et al., 1981; Pelletier, 1983; Arluison et al., 1984; Bouyer et al., 1984; Buijs et al., 1984; Onteniente et al., 1984; Voorn et al., 1986). The reported absence of synaptic relations of dopaminergic terminals in the posterior pituitary and the median eminence (Ajika \& Hökfelt, 1973; Cuello \& Iversen, 1973; Chetverukhin et al., 1979; Pelletier, 1983) may be considered a peculiar feature of the neuroendocrine system, but discrepancies in other brain regions may be attributed to technical problems and the use of different methods. However, the possibility cannot be excluded that there exist regional differences as suggested by the work of Séguéla et al. (1988) in the anteromedial and suprarhinal cortex of the rat. The findings reported here, based primarily on serial section analysis of DA-labelled axon terminals and axonal varicosities, strongly suggest that the action of DA in the cerebral cortex is mediated through specialized junctions.

\section{Acknowledgements}

We thank Dr M. Geffard for the dopamine antiserum. The work was supported by the Nuffield Foundation.

\section{References}

AJIKA, K. \& HÖKFELT, T. (1973) Ultrastructural identification of catecholamine neurones in the hypothalmic periventricular - arcuate nucleus - median eminence complex with special reference to quantitative aspects. Brain Research 57, 97-117.

ARLUISON, M., DIETL, M. \& THIBAULT, J. (1984) Ultrastructural morphology of dopaminergic nerve terminals and synapses in the striatum of the rat using tyrosine

hydroxylase immunocytochemistry: A topographical study. Brain Research Bulletin 13, 268-85.

BEAUDET, A. \& DESCARRIES, L. (1978) The monoamine innervation of rat cerebral cortex: Synaptic and nonsynaptic axon terminals. Neuroscience 3, 851-60.

BERGER, B., TASSIN, J. P., BLANC, G., MOYNE, M. A. \& THIERRY, A. M. (1974) Histochemical confirmation for dopaminergic innervation of the rat cerebral cortex after 
destruction of the noradrenergic ascending pathways. Brain Research 81, 332-7.

BERGER, B., THIERRY, A. M., TASSIN, J. P. \& MOYNE, M. A. (1976) Dopaminergic innervation of the rat prefrontal cortex: A fluorescence histochemical study. Brain Research 106, 133-45.

BERGER, B., TROTTIER, S., VERNEY, C., GASPAR, P. \& ALVAREZ, C. (1988) Regional and laminar distribution of the dopamine and serotonin innervation of the macaque cerebral cortex: A radioautographic study. Journal of Comparative Neurology 273, 99-119.

BERGER, B., VERNEY, C., ALVAREZ, C., VIGNY, A. \& HELLE, K. B. (1985) New dopaminergic terminal fields in the motor, visual (area 18b) and retrosplenial cortex in the young and adult rat. Immunocytochemical and catecholamine histochemical analyses. Neuroscience 15, 983-98.

BJÖRKLUND, A. \& LINDVALL, O. (1984) Dopaminecontaining system in the CNS. In Handbook of Chemical Neuroantomy, Vol. 2: Classical Neurotransmitters in the CNS, Part I (edited by BJÖRKLUND, A. \& HÖKFELT, T.), pp. 55-122. Amsterdam: Elsevier.

BOUYER, J. J., JOH, T. H. \& PICKEL, V. M. (1984) Ultrastructural localization of tyrosine hydroxylase in rat nucleus accumbens. Journal of Comparative Neurology 227, 92-103.

BUIJS, R. M., GEFFARD, M., POOL, C. W. \& HOORNEMAN, E. M. D. (1984) The dopminergic innervation of the supraoptic and paraventricular nucleus. A light and electron microscopical study. Brain Research 323, 65-72.

CARTER, D. A. \& FIBIGER, H. C. (1977) Ascending projections of presumed dopamine-containing neurons in the ventral tegmentum of the rat as demonstrated by horseradish peroxidase. Neuroscience 2, 569-76.

CHETVERUKHIN, V. K., BELENKY, M. A. \& POLENOV, A. L. (1979) Quantitative radioautographic light and electron microscopic analysis of the localization of monoamines in the median eminence of the rat. I. Catecholamines. Cell and Tissue Research 203, 469-85.

CUELLO, A. C. \& IVERSEN, L. L. (1973) Localization of tritiated dopamine in the median eminence of the rat hypothalamus by electron microscope autoradiography. Brain Research 63, 474-8.

DESCARRIES, L., BOSLER, O., BERTHELET, F. \& DES ROSIERS, M."H. (1980) Dopaminergic nerve endings visualised by high resolution autoradiography in adult rat neostriatum. Nature 284, 620-2.

DESCARRIES, L., LEMAY, B., DOUCET, G. \& BERGER, B. (1987) Regional and laminar density of the dopamine innervation in adult rat cerebral cortex. Neuroscience 21, 807-24.

DOUCET, G., DESCARRIES, L. \& GARCIA, S. (1986) Quantification of the dopamine innervation in adult rat neostriatum. Neuroscience 19, 427-45.

DOUCET, G., DESCARRIES, L., AUDET, M. A., GARCIA, S. \& BERGER, B. (1988) Radioautographic method for quantifying regional monoamine innervations in the rat brain. Application to the cerebral cortex. Brain Research 441, 233-59.

EMSON, P. C. \& KOOB, G. F. (1978) The origin and distribution of dopamine-containing afferents to the rat frontal cortex. Brain Research 142, 249-67.
EMSONं, P. C. \& LINDV ALL, O. (1979) Distribution of putative neurotransmitters in the neocortex. Neuroscience 4, 1-30.

ESPINOZA, S. G. \& THOMAS, H. C. (1983) Retinotopic organization of striate and extrastriate visual cortex in the hooded rat. Brain Research 272, 137-44.

FALLON, J. H., KOZIELL, D. A. \& MOORE, R. Y. (1978) Catecholamine innervation of the basal forebrain. II. Amygdala, suprarhinal cortex and entorhinal cortex. Journal of Comparative Neurology 180, 509-32.

FUXE, K. HÖKFELT, T., JOHANSSON, O., JONSSON, G., LIDBRINK, P. \& LJUNGDAHL, A. (1974) The origin of the dopamine nerve terminals in limbic and frontal cortex. Evidence for meso-cortico dopamine neurons. Brain Research 82, 349-55.

GEFFARD, M., BUIJS, R. M., SÉGUÉLA, P., POOL, C. W. \& LE MOAL, M. (1984) First demonstration of highly specific and sensitive antibodies against dopamine. Brain Research 294, 161-5.

HARIK, S. I. (1984) Locus coeruleus lesion by local 6hydroxydopamine infusion causes marked and specific destruction of noradrenergic neurons, long-term depletion of norepinephrine and the enzymes that synthetize it, and enhanced dopaminergic mechanisms in the ipsilateral cerebral cortex. Journal of Neuroscience 4, 699-707.

HERKENHAM, M. (1980) Laminar organization of thalamic projections to the rat neocortex. Science 207, 532-5.

HÖKFELT, T., FUXE, K., JOHANSSON, O. \& LJUNGDAHL, A (1974a) Pharmaco-histochemical evidence of the existence of dopamine nerve terminals in the limbic cortex. European Journal of Pharmacology 25, 108-12.

HÖKFELT, T., LJUNGDAHL, A., FUXE, K. \& JOHANSSON, O. (1974b) Dopamine nerve terminals in the rat limbic cortex: Aspects of the dopamine hypothesis of schizophrenia. Science 184, 177-9.

LEVITT, P. \& MOORE, R. Y. (1978) Noradrenaline neuron innervation of the neocortex in the rat. Brain Research 139, 219-31.

LEVITT, P., RAKIC, P. \& GOLDMAN-RAKIC, P. (1984) Regionspecific distribution of catecholamine afferents in primate cerebral cortex: A fluorescence histochemical analysis. Journal of Comparative Neurology 227, 23-36.

LEWIS, M. S., MOLLIVER, M. E,.., MORRISON, J. H. \& LIDOV, H. G. W. (1979) Complementarity of dopaminergic and noradrenergic innervation in anterior cingulate cortex of the rat. Brain Research 164, 328-33.

LINDVALL, O. \& BJÖRKLUND, A. (1984) General organization of cortical monoamine systems. In Monoamine Innervation of Cerebral Cortex (edited by DESCARRIES, L., READER, T. R. \& JASPER, H. H.), pp. 9-40. New York: Alan R. Liss.

LINDVALL, O., BJÖRKLUND, A. \& DIVAC, I. (1978) Organization of catecholamine neurons projecting to the frontal cortex in the rat. Brain Research 142, 1-24.

LINDVALL, O., BJÖRKLUND, A., MOORE, R. Y. \& STEVENI, U. (1974) Mesencephalic dopamine neurons projecting to neocortex. Brain Research 81, 325-31.

MILLER, M. W. \& VOGT, B. A. (1984a) Direct connections of rat visual cortex with sensory, motor, and association cortices. Journal of Comparative Neurology 226, 184-202.

MILlER, M. W. \& VOGT, B. A. (1984b) Heterotopic and 
homotopic callosal connections of rat visual cortex. Brain Research 297, 75-89.

MONTERO, V. M., ROJAS, A. \& TORREALBA, F. (1973) Retinotopic organization of striate and peristriate visual cortex in the albino rat. Brain Research 53, 197-201.

MOORE, R. Y. \& CARD, J. P. (1984) Noradrenaline-containing neuron systems. In Chemical Neuroanatomy, Vol. 2: Classical Transmitters in the CNS, Part I (edited by BJÖRLUUND, A. \& HÖKFELT, T.), pp. 123-56. Amsterdam: Elsevier.

MORRISON, J. H. \& FOOTE, S. L. (1986) Noradrenergic and serotonergic innervation of cortical, thalamic, and tectal visual structures in old and new world monkeys. Journal of Comparative Neurology 243, 117-38.

NGUYEN-LEGROS, J., BERGER, B. \& ALVAREZ, C. (1981) High resolution radioautography of central dopaminergic fibers labelled in vitro $\left[{ }^{3} \mathrm{H}\right]$ dopamine or $\left[{ }^{3} \mathrm{H}\right]$ norepinephrine. Brain Research 213, 265-76.

ONTENIENTE, B., GEFFARD, M. \& CALAS, A. (1984) Ultrastructural immunocytochemical study of the dopaminergic innervation of the rat lateral septum with anti-dopamine antibodies. Neuroscience 13, 385-93.

PALKOVITS, M., ZABORSKY, L., BROWNSTEIN, M. J., FEKETE, M. I. K., HERNAN, J. P. \& KANYICSKA, B. (1979) Distribution of norepinephrine and dopamine in cerebral cortical areas of the rat. Brain Research Bulletin 4, 593-601.

PAPADOPOULOS, G. C., PARNAVELAS, J. G. \& BUIJS, R. M. (1987) Light and electron microscopic immunocytochemical analysis of the serotonin innervation of the rat visual cortex. Journal of Neurocytology 16, 883-92.

PAPADOPOULOS, G. C., PARNAVELAS, J. G. \& BUIJS, R. M. (1989) Light and electron microscopic immunocytochemical analysis of the noradrenaline innervation of the rat visual cortex. Journal of Neurocytology 18, 1-10.

PELLETIER, G. (1983) Identification of endings containing dopamine and vasopressin in the rat posterior pituitary by a combination of radioautography and immunocytochemistry at the ultrastructural level. Journal of Histochemistry and Cytochemistry 31, 562-4.

READER, T. A. (1981) Distribution of catecholamines and serotonin in the rat cerebral cortex: absolute levels and relative proportions. Journal of Neural Transmission 50, 13-27.

SÉGUÉLA, P., WATKINS, K. C. \& DESCARRIES, L. (1988) Ultrastructural features of dopamine axon terminals in the anteromedial and the suprarhinal cortex of adult rat. Brain Research 442, 11-22.

SUKEKAWA, K. (1988) Interconnections of the visual cortex with the frontal cortex in the rat. Journal für Hirnforschung 29, 83-93.

SWANSON, L. W. (1982) The projections of the ventral tegmental area and adjacent regions: A combined fluorescent retrograde tracer and immunofluorescence study in the rat. Brain Research Bulletin 9, 321-53.

TASSIN, J. P., BOCKAERT, J., BLANC, G., STINUS, L., THIERRY, A. M., LAVIELlE, S., PRÉMONT, J. \& GLOWINSKI, J. (1978) Topographical distribution of dopaminergic innervation and dopaminergic receptors of the anterior cerebral cortex of the rat. Brain Research 154, 241-51.

TASSIN, J. P., LAVIELLE, S., HERVÉ D., BLANC, G., THIERRY, A. M., ALVAREZ, C., BERGER, B. \& GLOWINSKI, J. (1979) Collateral sprouting and reduced activity of the rat mesocortical dopaminergic neurons after selective destruction of the ascending noradrenergic bundles. Neuroscience 4, 1569-82.

THIERRY, A. M., BLANC, G., SOBEL, A., STINUS, L. \& GLOWINSKI, J. (1973a) Dopaminergic terminals in the rat cortex. Science 182, 499-501.

THIERRY, A. M., STINUS, L., BLANC, G. \& GLOWINSKI, J. (1973b) Some evidence for the existence of dopaminergic neurons in the rat cortex. Brain Research 50, 230-4.

TÖRK, I. \& TURNER, S. (1981) Histochemical evidence for a catecholaminergic (presumably dopaminergic) projection from the ventral mesencephalic tegmentum to visual cortex in the cat. Neuroscience Letters 24, 215-9.

TORREALBA, F., OLAVARRIA, J. \& CARRASCO, M. A. (1984) Cortical connections of the anteromedial extrastriate visual cortex in the rat. Experimental Brain Research 56, 543-9.

VAN EDEN, C. G., HOORNEMAN, E. M. D., BUIJS, R. M., MATTHIJSSEN, M. A. H., GEFFARD, M. \& UYLINGS, H. B. M. (1987) Immunocytochemical localization of dopamine in the prefrontal cortex of the rat at the light and electron microscopical level. Neuroscience 22, 849-62.

VOORN, P., JORRITSMA-BYHAM, B., VAN DIJK, C. \& BUIJS, R. M. (1986) The dopaminergic innervation of the ventral striatum in the rat: A light- and electron-microscopical study with antibodies against dopamine. Journal of Comparative Neurology 251, 84-99.

WILSON, C. J., GROVES, P. M. \& FIFKOVA, E. (1977) Monoaminergic synapses, including dendro-dendritic synapses in the rat substantia nigra. Experimental Brain Research 30, 161-74. 